\title{
José Antonio del Busto, biógrafo de Santa Rosa, maestro de la peruanidad
}

\author{
José Antonio Benito \\ Universidad Católica Sedes Sapientiae \\ Facultad de Teología Pontificia y Civil de Lima
}

El 2017 ha conmemorado el primer centenario de la emblemática Pontificia Universidad Católica del Perú y el cuarto centenario del tránsito celestial de Rosa de Santa María, la santa universal. En la mencionada casa de estudios se formó y sentó cátedra el maestro José Antonio del Busto. Entre sus concienzudas biografías dedicadas a los grandes forjadores del Perú, destaca -como singular y señera- la dedicada a Isabel Flores de Oliva. Fue su última obra publicada en vida. ${ }^{1}$ En el pórtico del libro esculpe la escueta y sentida dedicatoria con sabor a testamento: "A la Pontificia Universidad Católica del Perú, cuya patrona es Santa Rosa de Lima". Una buena oportunidad para agradecerle y recordarle. Cabe mencionar que, en las dos conmemoraciones, el recordado profesor Del Busto ha sido continuamente citado. Con estos apuntes sobre su vida y obra, quiero sumarme a las numerosas muestras de gratitud que con motivo del décimo aniversario de su partida le han brindado.

\section{Un historiador con mucha historia}

Hijo de Angélica Duthurburu y José Antonio del Busto nació en Barranco 1932. Su cariño por la historia comenzó desde aquel momento en que su mamá lo motivó ante un plato de arroz con frijoles en el que le dijo: come el arroz blanco, como los españoles; y ahora, los frijoles cobrizos como los indios. Luego de graduarse en el colegio San Luis de Barranco ingresó a la Universidad Católica. Su actividad docente se inició en 1953 en condición de instructor del preseminario que estaba a cargo del doctor Luis Jaime Cisneros en el antiguo local de la plaza Francia, donde funcionaba la Universidad. Tras asumir la cátedra de Historia del Perú, muchas generaciones de estudiantes de diferentes carreras han gozado del estudio de los orígenes de la civilización peruana. Con 25 años de edad, obtuvo el grado de doctor en Historia y Geografía. Con

\footnotetext{
${ }^{1}$ José Antonio del Busto Duthurburu, Santa Rosa de Lima (Isabel Flores de Oliva). Lima, Pontificia Universidad Católica del Perú, 2006.
} 
el tiempo llegó a ser profesor principal de la Universidad Católica, donde fue también decano de la Facultad de Letras y Ciencias Humanas. También ejerció la docencia en la Escuela Militar de Chorrillos y en la Escuela de Aviación de las Palmas. Ha sido director general del Instituto Nacional de Cultura (19831984), miembro de la Academia Nacional de Historia, miembro honorario de la Academia Peruana de la Lengua Quechua y miembro corresponsal de la Real Academia Española de Historia. También ha pertenecido al Instituto Nacional de Estudios de Túpac Amaru y el Instituto Peruano de Historia del Derecho. Finalmente fue miembro correspondiente de la Academia Nacional de Historia de la República Argentina, de la Academia de Ciencias de Buenos Aires y del Centro Nacional de Investigaciones Genealógicas y Antropológicas de Quito.

Su labor mereció diversas distinciones de muchas universidades e instituciones. En 1968 obtuvo el Premio Nacional de Cultura Inca Garcilaso de la Vega. El Reino de España lo reconoció como Comendador de la Orden de Alfonso X el Sabio (1974) y nuevamente distinguido con la Orden de Isabel la Católica (2002).

Aparte de más de un centenar de artículos en revistas especializadas, destacamos de entre sus cincuenta libros algunos títulos señalados: El conde de Nieva, virrey del Perú (1963), La tesis universitaria (1965), Historia de los descubrimientos geográficos, siglos V al XV (1973), Historia marítima del Perú (dos volúmenes del tomo III, 1973); Historia general del Perú (los tomos de Perú antiguo, 1970; y Descubrimiento y conquista, 1978). José Gabriel Túpac Amaru antes de su rebelión (1981), Los trece de fama (1988), San Martín de Porras/Martín de Porras Velásquez (1993). Fundadores de ciudades en el Perú (1995).

Otra veta abierta se refiere a sus estampas testimoniales de personas, lugares y viajes: Historia y leyenda del viejo Barranco (1985), Los peruanos en la Antártida (1989), La tierra y la sangre de Francisco Pizarro (1993), Barranco: personajes de ayer (1993). Elaboró un catálogo comentado de la colección Enrico Poli, La platería en el Perú: dos mil años de arte e historia (1996). Por último, son también destacadas obras suyas: Historia de la minería en el Perú (1999), Túpac Yupanqui, descubridor de Oceanía (2000), Breve historia de los negros del Perú (2001), Conquista y Virreinato (tomo 3 de la Enciclopedia Temática del Perú, que publicó el año 2004, el diario El Comercio), y finalmente la mencionada biografía: Santa Rosa de Lima (2006).

Al preguntarle acerca de la mayor satisfacción que le ha deparado su labor como investigador, no dudó en responder que era la realización personal. Encontrar la verdad mediante la búsqueda es ir de lo conocido a lo desconocido y convertir lo desconocido en conocido. Por eso consideraba que su trabajo era su recreo. Su labor había sido una ininterrumpida satisfacción durante toda la vida. Al pedirle uno de mis alumnos un consejo sobre la vocación por la historia, nos puso el símil del matrimonio. “En la elección de esposa -le respondió a un 
alumno- lo primero es que te guste, luego que sea buena, que te comprenda que te quiera."

\section{Historiador de la peruanidad}

El librito Tres ensayos peruanistas (Lima 1998) recoge tres estudios, magistrales por su sencillez y profundidad. El primero, Perú esencial, nos ofrece su visión peruanista del Perú, a través de tres dimensiones de la realidad histórica: como patria (nacida hace 15.000 años con el ingreso de los primeros cazadores nómadas a nuestro territorio), nación (surgida en el siglo XVI con los primeros mestizos, especialmente con Garcilaso) y estado (libre y soberano desde el 28 de julio de 1821 con la Independencia. Su determinación de autonomía le convierte en país "independiente, uninacional, pluricultural, multilingüe y mestizo". El segundo, el más extenso, El mestizaje en el Perú, nos brinda la lección inaugural del año académico de 1992 ofrecida en la Universidad de Piura. Parte del mestizaje racial para centrarse en el cultural, poderosamente desarrollado en la comida, el vestido, la habitación, la música, la danza, la pintura, la literatura, la artesanía y la religión. El último de los artículos se titula: En torno al monumento a Pizarro y fue publicado en el diario El Comercio el 29 de abril de 1997. Son reflexiones acerca de la polémica del monumento ecuestre de Francisco Pizarro. Reconoce que el extremeño "no nos conquistó a nosotros, sino a los hombres del incario que son nuestros antepasados cobrizos. Nosotros descendemos de los vencidos y de los vencedores, pero no somos vencedores ni vencidos. Somos el resultado de ese encuentro. Podemos ser indigenistas e hispanistas, pero por encima de todo debemos ser peruanistas. El peruanismo une, cicatriza; el indigenismo y el hispanismo mal entendidos dividen, descuartizan. Nuestra obligación es integrarnos, no desintegrarnos".

Casi todos los escolares han estudiado la historia del Perú en sus magníficos textos. Coordinó el gran proyecto editorial BRASA “Forjadores del Perú" en 30 fascículos (1994-1996), proyecto lamentablemente truncado ya que iban a desfilar más de 100 peruanos ilustres seleccionados por él. En la misma editorial coordinó Historia general del Perú (1993) en nueve volúmenes.

\section{Sabía más de Pizarro que el propio conquistador}

La frase es de uno de sus cientos de alumnos que se sintió cautivado con la magia personal de narrar la historia. El doctor Del Busto sabía hasta "qué pensaba Francisco Pizarro". Recuerdo su magnífica conferencia en la Universidad Católica Sedes Sapientiae de Lima para inaugurar nuestro seminario: “Forjadores de la peruanidad". Nos habló sobre "lo que el Perú tiene por la presencia de Pizarro", y que sería publicado en El Comercio y en nuestra revista Studium. En su estilo inconfundible, escueto, directo, vibrante, nos adelantó de entrada sus

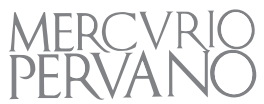


conclusiones: "Se puede hablar de Pizarro sin el Perú, pero no se puede explicar el Perú sin Pizarro. Hagamos la prueba, resulta imposible. Luego, nos guste o disguste, es pieza inamovible de nuestro pasado. La lista anunciada no es larga pero sí importante. Se puede enumerar así: el Perú tiene hoy, debido a la presencia de Pizarro, los siguientes hechos: su descubrimiento; su nombre; su ingreso a la historia, a la geografía y a la cronología modernas; su territorio mayoritario; la Amazonía; las principales ciudades; la cultura occidental; la lengua española; la religión cristiana; el mestizaje; la nación en su momento; y la cultura peruana".

Al hablar del cristianismo, nos dijo: "Pizarro no era un santo ni pretendía serlo, pero fue el implantador del cristianismo en el Perú. Lo trajo en su versión española, el catolicismo, y esta fe, predicada bien o mal a todo el territorio, fue la primera unidad que hemos tenido. La religión católica conllevó su dogma y su moral. Nos enseñó a diferenciar, a la cristiana manera, lo bueno y lo malo, lo justo y lo injusto, lo derecho y lo falso. En esto el cristianismo se adelantó con su prédica en muchos siglos a la proclamación de los Derechos Humanos".

La biografía está hecha por un peruano mestizo y para todos los peruanos; porque Perú está formado por todas las sangres. La profesionalidad del historiador le impide hacer su apología, por lo que nos brinda un estudio científico con sentido común y apreciación serena de su biografía. Del Busto reconoce que el extremeño "no nos conquistó a nosotros, sino a los hombres del incario que son nuestros antepasados cobrizos. Nosotros descendemos de los vencidos y de los vencedores, pero no somos vencedores ni vencidos. Somos el resultado de ese encuentro. Podemos ser indigenistas e hispanistas, pero por encima de todo debemos ser peruanistas. El peruanismo une, cicatriza; el indigenismo y el hispanismo mal entendidos dividen, descuartizan. Nuestra obligación es integrarnos, no desintegrarnos". A la visión de los vencedores y a la visión de los vencidos ha sucedido la visión de los mestizos. Somos rebisnietos de Manco Cápac y rebisnietos del Cid. A los peruanos no nos van a decir cómo tenemos que ser, ahora nosotros decimos quiénes somos. Y este mestizaje es positivo, significa unión, cohesión progreso, estabilidad, potencialidad y realización (II p.546.

Los cientos de citas documentales, así como los apéndices: la cronología del Tahuantinsuyo, la genealogía de Pizarro (el árbol del porquerizo) dan cuenta de su rigurosidad. La organización de la obra revela su claridad: los trabajos y los días, la marcha de Pizarro de Tumbes a Poechos, de Tangarará a Cajamarca, de Cajamarca a Pachacamac, la lista del oro y de la plata, la marcha de Cajamarca a Cusco) nos prueban los sólidos cimientos en que construye su obra basándose en manuscritos, crónicas, probanzas, cartas... En conclusión, es la biografía "definitiva" de Pizarro. Y a pesar de la evidente erudición la obra se lee de un tirón.

\section{Santa Rosa y San Martín en carne y hueso}

Como otrora Miguel Ángel con sus esculturas, el doctor Del Busto supo dar alma, corazón y vida a sus personajes. Dejando de lado almibaradas hagiografías 
de santos acartonados, nos brinda un estilo de hacer santos, de carne y hueso, creíbles, vivibles. Parafraseando lo que se decía del Cid Campeador, el autor es "largo en facellas" (recopilación) y "corto en narrallas" (redacción). Tal sucede con la dedicada a Santa Rosa. La obra se nos antoja en su diseño como un Escorial, labrado con austeridad herreriana y claridad meridiana. Dos partes, correspondientes a los dos ambientes en los que discurre la vida de Rosa, la casa del arcabucero Gaspar de Flores y la casa del contador Gonzalo de la Maza. A la primera se dedican quince capítulos, a la segunda doce. Todos los capítulos están subdivididos en tres apartados; unos -como el primero dedicado a la familia- de lógica aplastante: padre, madre, hermanos; otros -como el de las devociones- teológicamente perfectos: el culto de latría, el culto de hiperdulía, el culto de dulía; algunos, provocando hilaridad: "la doncellica (niña graciosa de 12 a 14 años), la doncelluela (muchacha donosa de 15 a 17), la doncelleja (moza apta para ser esposa, de 18 a 20); otros ofrecen experiencias extrañas, un tanto acomodadas: el maestro cantero, la visión del Justo Juez, el enigma de las rosas. Tan sólo un asunto -el de la penitencia- requiere dos capítulos, el primero "los guantes de piel de buitre, los cilicios de metal, la corona de púas", y el segundo "la alcayata, la cadena, la corona de púas". Los títulos, a manera de ráfagas rápidas y de nombre sonoro, en número 84 , agilizan la lectura. Las palabras, netamente castizas, sin concesión alguna al neologismo, muchas veces divertidas; así nos dirá que "María de Oliva, su esposa (de Gaspar Flores), era la que llevaba la voz cantante, sonante y tronante" pp. 103-104. Otras, presenta vocablos inusuales como "se penitenciaba" (p. 129).

La obra sigue un orden cronológico, lineal, muy claro, al tiempo que dotado de una rica contextualización. Aunque principia confesándonos que "escribir sobre Rosa de Santa María no ha sido fácil", sin embargo, al auscultar a la "mujer, a la mujer ascética y a la mujer santa" queda satisfecho. Destaca que gracias ella, "desde un ángulo nuevo, desconocido, se unificó el Perú". Y se explica con honestidad:

Fue la primera gran unidad que hemos tenido. El orgullo criollo y mestizo, así como el de los indios y de los negros, fue el factor preponderante de todo ello. España lo reconoció y Roma hizo el resto. (p. 15)

Señala que Rosa de Lima, si no fue mestiza de raza, lo que no considera más que posible apoyándose en el testimonio de fray Gonzalo Tenorio, que habla de que sus abuelos "maternos fueron indios", fue "mestiza por aclamación" (p. 15).

Nadie tan universal como Rosa. Difícilmente se puede concebir Lima sin ella. El autor no olvida el entrañable nombre que los limeños han dado a las golondrinas que con sus plumas blanquinegras recuerdan el hábito de Rosa: las "santarrositas".

Lo mismo había sucedido con la biografía de San Martín. Más allá del mito y de la leyenda creada en torno al taumaturgo "santo de la escoba" hay

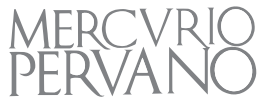


que rescatar -como lo ha hecho magistralmente Del Busto- su entrañable humanidad, la gran responsabilidad con la que vivió su vocación. Al respecto dirá su compañero fray Juan de Barbarán, que todo el tiempo que fue religioso "tocó a maitines y al alba", y de forma tan vigilante que "enmendaba el reloj y tan perseverante que nunca dejó de oírse esta salva a la aurora". En su profesión de lavandero destacó por la pulcritud con que dejaba la ropa.

El autor delinea con precisión el contexto limeño y el pensamiento de la época: "crepúsculo quinientista y el amanecer barroco", para presentarnos a un Martín de Porras creíble por el realismo del personaje: "Martín de Porras Velásquez, gentilhombre de escoba, barbero sangrador, mulato socarrón, flor de Malambo" (p. 27). A pesar del gran aparato de notas documentales, la lectura cautiva por su magia narrativa. Imprescindible para conocer el auténtico hombre y santo dominico.

La fuente principal es la documentación del proceso de beatificación y del mismo se conocen las declaraciones de los testigos que vieron, conocieron y trataron a fray Martín, dejando para un segundo lugar a los que sólo oyeron hablar de él y se acogen a lo que fue público y notorio. El autor lo somete al método de la contraposición y del análisis, para deslindar errores, fraudes, fantasías.

El doctor del Busto presenta siempre a las claras su modo de hacer historia: "Saberse trasladar al pasado como primera actitud del historiado con el fin de reconstruir "el pasado como pasado, tal como fue y no como creemos que fue, tal como sucedió y no como quisiéramos que hubiese sucedido" p. 13. El resultado de su labor es satisfactorio:

Hoy hemos reconstruido su vida y nos ha dejado satisfechos. Lo hemos sacado del mito y de la leyenda, de la tradición y de la sensiblería popular para ubicarlo en el terreno histórico y darnos en definitiva como el hombre. Podemos decir que lo hemos llegado a conocer como personaje histórico y concluimos que, en la Lima de ese entonces, ciudad entre beata y pecadora, urbe de embrujos y milagros que en todo veía la mano de Dios o las uñas del diablo, vivió un hombre santo. Era limeño, bastardo, mulato y donado, y su vida fue tan virtuosamente llevada que resulta explicable que la gente empezara a mirarlo como un logrado caso de santidad". (p. 14)

Tuve la suerte de entrevistarle para un programa de TV y le comenté que se observaba en su obra una pretensión inicial de objetividad y casi distancia hacia el personaje, pero que a medida que va avanzando el libro, le gana el personaje y como que le cobra un gran cariño. Me respondió:

Yo quedé muy contento de esto, tan contento que a veces el lector se da cuenta, en vista que descubrí ese personaje triple en uno: el hombre común, el hombre superdotado por una serie de cosas parapsicológicas y en tercer lugar, acaso el primero, el hombre santo. Algo muy difícil de negar, pero que 
desconcierta, finalmente. Si uno no ve el sol ve su resplandor, así que esto fue un poquito lo que hice yo.

Tuve la suerte de participar también como comentarista en la presentación de su obra sobre Santa Rosa, lo que constituiría su última intervención pública. Minutos antes del evento -tal como era su costumbre, y a pesar del cáncer que minaba su organismo- bromeaba y se convertía en el centro de la tertulia. Escuchó los elogiosos comentarios sobre su persona y su obra y, al concluir, sin ningún apunte en la mano, con tono decidido pronunció sublimes palabras que bien pudieran denominarse su testamento como historiador, hombre, cristiano. Nos habló de su visión como historiador, su recelo por airear demasiado lo bueno y disimular lo débil.

Al acercarse a Santa Rosa la encontró dedicada y profunda, sin nada negativo y con sólo cosas buenas. Al igual que con san Martín quería someterla a la prueba de la crítica histórica y creía haber logrado un estudio sólido. Tanto uno como otra se merecen una estatua de piedra, de tal manera que quienes los atacan no los conocen. Los santos no son comunes, pero son normales, son heroicos. Ser santo no es sólo hacer el bien y hacer maravillas; es hacer lo ordinario de modo extraordinario. Con Rosa se han cebado en decir que era loca, visionaria, exagerada. Pobrecita; sufrió algunas enfermedades dolorosas, pero era una mujer muy fuerte; la veo muy difícil de atacar.

En la historia y en la vida uno se encuentra con personajes normales y anormales. San Martín y santa Rosa son dos santos muy limpios en el proceder, no se les puede atacar; no hay que defenderlos, no lo necesitan.

Como en todas las biografías y en mis obras he tenido muy presente a Parménides "lo que es y lo que no es no es". Por esto hay que enfrentar a los falsos santos. No es cristiano querer ser y luego no ser. Hay que serlo. Aparentarlo ya es vanidad.

Debemos destacar la presencia de la santidad en el Perú. Al estudiar los santos peruanos, tenía la convicción de que lo nuestro peruano debía de quedar muy claro. Yo, desconfiado por naturaleza, llegué a la conclusión de que todo era muy bonito; el mundo de los santos era muy interesante, muy equilibrado. Su mundo es fascinante y muy profundo. Uno encuentra el amor de Dios, el amor a Dios, el amor por Dios. A Santa Rosa y a San Marín si se quita su conducta por este amor a Dios no se les entiende.

\section{Túpac Yupanqui y la aventura}

Acaba de ser editado en la Universidad de Piura el libro: Túpac Yupanqui, el Resplandeciente, en dos tomos, dedicados a sus facetas de conquistador y gobernante. Hace más de una década que se publicó en dos ocasiones una versión resumida o reducida del primero: Túpac Yupanqui, descubridor de Oceanía, que recoge su teoría acerca de la expedición que habría realizado el inca a la

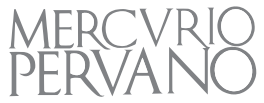


Polinesia. Para Del Busto, Túpac Yupanqui es el emperador ignorado, pues lo que sabemos de él demuestra que fue más que Pachacútec y más que Huayna Cápac. Fue un conquistador al que se ha querido halagar llamándolo el Alejandro Magno del Nuevo Mundo. Los actuales límites del Perú se los debemos a él, que los conquistó, y a Francisco Pizarro, que los resguardó. Túpac Yupanqui hizo ocho campañas militares que son notables. Dos al Chinchaysuyo, dos al Contisuyo, dos al Collasuyo, dos al Antisuyo, todo el territorio actual del Perú.

El punto de partida fue La historia índica de Pedro Sarmiento de Gamboa, y las crónicas escritas por Miguel Cabello de Balboa y fray Martín de Murúa. Su teoría la inició en 1967 cuando visitó Oceanía. Se apoya en que en las Marquesas hay unas ruinas que se atribuyen al rey Tupa, el cual vino de un país donde nacía el sol, a través del mar, en una flota de balsas. En Mangareva se conserva la leyenda del rey Tupa, que llegó a través de un estrecho que hasta hoy lleva su nombre y en donde se baila "la danza del rey Tupa". Tanto impacto causó que, quinientos años después, los isleños de Mangareva no lo olvidan. Túpac llevó la edad de los metales a un pueblo que vivía en la edad de piedra.

José Antonio del Busto fue un impertérrito aventurero. Ha surcado los mares alcanzando la Polinesia o la Antártida. Ha recorrido el Amazonas a remo. También fue torero, los últimos años de secundaria y al comienzo de sus estudios universitarios. El mismo espíritu valiente lo ha llevado hasta escribir sobre las vidas inolvidables de santa Rosa y otros peruanos irrepetibles.

\section{¡Gracias y adiós!}

Se lo dice su esposa Teresa Guerin y sus cuatro hijas. La Universidad Católica a la que consagró su vocación a la enseñanza formando legiones de historiadores y apasionados por el Perú. Las numerosas instituciones de la que ha sido miembro y responsable. Se lo dice el Perú y la Iglesia. Por mi parte, siempre vi en el doctor José Antonio del Busto un hidalgo universal al tiempo que embajador de la peruanidad. Duro como el granito de El Escorial o los muros ciclópeos de Sacsahuamán a la hora de trabajar, pero blando como la nieve de la sierra de Granada o la espuma de la costa barranquina a la hora de dar. Rigurosa objetividad de arquitecto milimétrico pero pujante y creativa vitalidad de poeta al hacer valer su rico yo. Conquistador del más, del primer lugar, a lo Pizarro, y conquistado por lo menos, el último lugar, a lo Martín de Porras Velázquez. Amigo de sumar (aventuras, sangres, culturas), enemigo de restar (flojera, materia, bazofia. Siempre en vela, valiente, señalando que la meta está siempre más allá. Explorador de nuevos mundos a lo Túpac Yupanqui y excelente y simpático narrador.

Gracias por el ejemplo. Nuestro adiós es un compromiso con la Universidad, a la que alentó por su juventud e ilusión, historia, con el Perú, con lo mejor de cada ser humano. Como recuerdo de su inolvidable visita a mi Universidad Católica Sedes Sapientiae estampó en el segundo tomo de su libro sobre Pizarro:

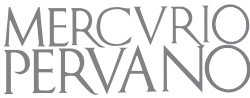


"A esta Universidad, con mucha esperanza, porque de verdad que tengo mucha esperanza en ella, con mis mejores deseos".

Pero José Antonio del Busto sigue vivo en sus libros, los publicados y los que con sorpresa vemos que se siguen publicando. Es el caso del editado con el manuscrito de sus memorias. El profesor Rodolfo Cerrón Palomino, en las palabras de presentación de la obra póstuma de José Antonio del Busto, ${ }^{2}$ nos compartió la etimología puquina de YUPANQUI, la que habría encantado al llorado maestro: significa 'señor digno de memoria'. Y me quedé con este mensaje, el doctor Del Busto había sido todo un "señor digno de memoria". De ahí que el Instituto se llenase -en argot taurino- hasta la bandera, y así el libro salió premiado con las dos orejas y el rabo. Los elogios -muy fundados si se ve el rico contenido y la excelente presentación- vertidos por los presentadores así lo ameritan. Desde Patricia Arévalo, directora del Fondo Editorial PUCP, alumna del maestro y amiga de su esposa y viuda Teresa, quien refirió la sinceridad sorprendente, sin miedo a la verdad de Antuco, valiente, aunque genere polémica; su vibración literaria, con pasión y erudición. El doctor Cerrón Palomino hiló un discurso del más puro castellano en el que destacó la virtud de la descripción, la magia de los nombres, el goce permanente de la investigación, la pasión por la peruanidad (la sentía desde el Instituto cuando escuchaba tocar la quena de un pobre ciego al unísono de las campanas de la iglesia de San Agustín), su espontaneidad y su amistad fruto de su profundidad; terminó glosando a Lope de Vega "a mis soledades voy, / de mis soledades vengo, / porque para andar conmigo / me bastan mis pensamientos".

El doctor José Agustín de la Puente recordó el año 1951 en que se acercó a la Universidad Católica para matricularse. Destacó el valor de la memoria autobiográfica, la suya tan limpia y tan libre, sin nada que defender ni que atacar, tan sólo compartir. Su personalidad firme, equilibrada, serena, coherente. Su vivencia familiar, hogareña, el cariño por Barranco, el colegio San Luis. Su interés por la geografía, el arte, lo cotidiano. Fue un maestro con el don de la evocación, sin ninguna incertidumbre, aprovechador del tiempo, hasta en la enfermedad. ¡Qué alegría sentí al evocar un gran maestro a un gran discípulo!

Teresa Guerin, su esposa y viuda, con una simpatía contagiosa, nos develó secretos de su esposo, como su pasión por la heráldica, la genealogía, su admiración por los conquistadores porque "se jugaron el todo por el todo". Una anécdota simpática de uno de los primos más allá del $4^{\circ}$ grado; al preguntarle que de dónde venía su apellido y responderle que no sabía, el doctor Del Busto le espetó: "Si no sabe de dónde viene cómo va saber dónde ir, jovencito...". La entrega y pasión por la historia que le llevó a hurgar hasta el fondo de sus personajes; de todos ellos quiso captar el lado positivo, hasta de Lope de Aguirre.

\footnotetext{
2 José Antonio del Busto Duthurburu Memorias de un historiador. Lima, Pontificia Univesidad Católica del Perú, 2008, p. 328.
}

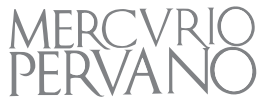


Aunque vibró con Túpac Yupanqui y Pizarro, llegó a la compenetración casi total con San Martín de Porras. En las memorias deja su pensamiento sobre el Perú y el mestizaje, deja ideas, propuestas. Por último, agradeció a los organizadores y presentadores, especialmente a Margarita Guerra, directora del IRA, al rector de la PUCP, y al doctor De la Puente a quien José Antonio del Busto le reconoció siempre como su maestro. Dicho sea de paso, pero Del Busto tenía tal pasión por el toreo que estuvo a punto seguir el arte de la tauromaquia y fue el maestro de la Puente quien le cambió de tercio y nos proporcionó una faena de primera.

En la sala estaban sus hijas, sus nietos, sus amigos... Sentimos su aliento y su fuerza. Y seguimos esperando sus obras. Se anunció el homenaje dedicado por sus amigos y discípulos, que hoy es realidad en dos tomos editados por los historiadores Margarita Guerra Martinière y Rafael Sánchez-Concha Barrios. En los mismos hemos participado historiadores, arquitectos, abogados, filósofos, lingüistas, arqueólogos, periodistas, entre otros investigadores entre los que destacan Guillermo Lohmann Villena, Mariana Mould de Pease, Santiago Agurto, Carlos Blancas, Federico Kauffmann Doig, Rodolfo CerrónPalomino, Juan Gargurevich Regal, Salomón Lerner Febres, Amalia Castelli, Oswaldo Holguín Callo, Juan de la Puente Candamo, Augusto Ortiz de Zevallos, Waldemar Espinoza Soriano, Martha Barriga Tello. Esta sección está antecedida por testimonios personales, artículos sobre patrimonio cultural y sobre teoría de la historia, que dan cuenta de la visión integradora que el doctor del Busto tenía de su disciplina. Que disfruten de la lectura de este libro de combate y de paz, de fuerza y hermandad, de hondura y relax.

La Universidad de Piura está próxima a publicar un libro en homenaje al profesor Del Busto, con el contenido de las Jornadas de Historia del año 2007 que llevaron por epígrafe "El historiador, su vida, el Perú", en referencia su persona $\mathrm{y}$ a su labor peruanista. En buena hora.

Recordar es recrear de modo cordial. Cuatro por cien, de Santa Rosa, cien de la PUCP, diez, ya diez, se dice bien, pero parece que fue ayer. Gracias, doctor, maestro y amigo, por volver a nuestro ser y querer. 